\title{
Reação de cultivares, efeito da quantidade de pontos e da época de inoculação e idade da espata no desenvolvimento da antracnose em antúrio
}

\author{
B eatriz M eireles B arguil' ${ }^{1}$, Sônia M aria A Ives de Oliveira ${ }^{1,2}$, Rildo Sartori Barbosa Coêlho ${ }^{1,2}$
}

${ }^{1} U$ niversidade F ederal Rural de Pernambuco, Departamento de A gronomia, Á rea de Fitossanidade, CEP 52171-900, Recife-PE, B rasil. E-mail: s.oliveira@ depa.ufrpe.br; ${ }^{2 B}$ olsista CnPq/UFRPE

A utor para correspondência: Sônia M. A. Oliveira

Data de chegada: 08/12/2006. A ceito para publicação em: 22/11/2007

\section{RESUMO}

Barguil, B. M .; Oliveira, S. M . A .; Coel ho, R. S. B. Reação de cultivares, efeito da quantidade de pontos e da época de inoculação e idade da espata no desenvolvimento da antracnose em antúrio. Summa Phytopathologica, v.34, n.2, p.156-160, 2008

0 antúrio é uma planta semi-herbácea de folhas verdes vistosas, formato cordiforme e inflorescências com espatas de diversas cores de acordo com a cultivar, onde tanto a folhagem quanto as inflorescências são de importância ornamental. A antracnose causada por Colletotrichum gloeosporioides é uma das principais doenças nessa cultura, estando presente em vários plantios comerciais brasileiros. Os sintomas manifestam-se sobre as folhas, na forma de lesões pardas predominantes nas bordas ou junto às nervuras. $\mathrm{N}$ as espatas ocorrem pequenas manchas escuras, que evoluem para uma podridão encharcada, prejudicando a comercialização das hastes. Essa pesquisa objetivou verificar o efeito da idade da espata, da quantidade de pontos e época de inoculação no desenvolvimento dos sintomas da antracnose, bem como a reação de cultivares de antúrio quando inoculadas com diferentes isolados de C. gloeosporioides $(\mathrm{Cg})$. A idade da espata influenciou o desenvolvimento da lesão para os dois isolados avaliados.
Em espatas no estádio 1, sem a completa abertura, as lesões formadas foram significativamente maiores do que aquelas formadas em espatas nos estádios 4 e 5 . As maiores lesões causadas pelos isolados do patógeno foram formadas com cinco pontos de ferimento nas duas cultivares de antúrio (cvs. Tropical e Cananéia). A época de inoculação não influenciou no tamanho da lesão, nas duas cultivares avaliadas. Os menores períodos de incubação (PI) para o isolado $\mathrm{Cg} 1$ foram observados nas cultivares A stral, Tropical, Netuno e Farao, diferindo significativamente das demais cultivares. Nas cultivares Sonate, A stral, Tropical, Netuno e Farao foram observados os menores $\mathrm{PI}$ para 0 isolado $\mathrm{Cg}$ 2. A menor área abaixo da curva de progresso da doença (AACPD) resultante da inoculação com $\mathrm{Cg} 1$ foi observada em Sonate, que diferiu das demais cultivares. As menores A ACPD ocasionadas pelo isolado $\mathrm{Cg} 2$ foram observadas em Laguna e Midori, que diferiram das cultivares Cananéia, Sonate, A stral, Tropical e Netuno.

Palavras-chave adicionais: Anthurium andraeanum, Colletotrichum gloeosporioides, flores tropicais.

\section{ABSTRACT}

B arguil, B. M ; Oliveira, S. M . A.; Coelho, R. S. B. Cultivars reaction and influence of inoculation points and time, and espathe age on anthracnose development on anthurium. Summa P hytopathologica, v.34, n.2, p.156-160, 2008

The anthurium is a semi-herbaceous plant with green leaves, of heart form and inflorescence with espathe of different colors changing with the cultivar both of ornamental importance. The antracnose caused by Colletotrichum gloeosporioides is one the most important diseases the crop, found in many Brazilian commercial fields. The symptoms develop on the leaves forming dark lesions usually dose to the vein. In the espathe, small dark lesions may occur devaluating the product for selling. This research had the objective of verifying the effect of espathe age, the quantity of inoculation points, as well as the reaction of anthurium cultivars when inoculated with different isolates of $\mathrm{C}$. gloeosporioides $(\mathrm{Cg})$. The age of the espathe influenced the lesion development for both isolates. On espathe estage 1 , not completed open, the lesions were significantly different from espathes on 4 and 5 estages. The biggest lesions were achieved with five wound points on the two cultivars (cvs. Tropical and Cananéia) and two isolates tested. The inoculation time did not influence the lesion size. The incubation period (IP) was variable with cultivars and isolate. The smallest IP for Cg 1 isolate were observed on CVA, A stral, Tropical, Netuno and Farao. On Sonate, A stral, Tropical, Netuno and Farao cultivars were observed the smallest IP for $\mathrm{Cg} 2$ isolate. The smallest A rea Under the Disease Progress Curve (AUDPC) were observed on Sonate for $\mathrm{Cg} 1$ and on Laguna and Midori for $\mathrm{Cg} 2$.

Additional keywords: Anthurium andraeanum, Colletotrichum gloeosporioides, tropical flowers.

0 antúrio (Anthurium andraeanum Linden), família A raceae, é uma planta semi-herbácea, ereta, perene, com al tura variando de 0,30 a 1,0 m, sendo originária da Colômbia e Venezuela. A presenta folhas verdes vistosas, com formato cordiforme e inflorescências com espatas de cores variadas de acordo com a cultivar, onde tanto a folhagem quanto as inflorescências são de importância ornamental $(7,12)$.

As cultivares comerciais de antúrio devem reunir diversas características como: qualidade da folha; haste floral ereta, firme e 
medindo 60 cm; espata com brilho, aberta, de textura firme e coloração uniforme; espádice ligeiramente arqueada e medindo cerca de dois terços do comprimento da espata; boa produção de hastes; durabilidade pós-colhei ta e também resistência às doenças $(12,13)$. 0 mel horamento de cul tivares visando resistência a doenças é uma característica desejável para a manutenção da produção das flores na presença de uma doença (4) e diversas medidas de controle devem ser tomadas para prolongar a durabilidade dessa resistência (1), como remoção de restos cul turais, irrigação por gotejamento e nutrição equilibrada (14).

No Brasil, as doenças relatadas em antúrio são a podridão das raízes (Phytophthora sp. ou Pythium sp.), a antracnose (Colletotrichum gloeosporioides (Penz.) Sacc.), a podridão negra (Phytophthora citrophthora (R.E.\& E.H.Smith) L eonian) afetando a parte aérea da planta, Pestalotiopsis guepinii ((Desm.) Stey) causando manchas necróticas em folhas e flores (2, 3, 9, 12). Dentre essas, destaca-se a antracnose por estar presente na maioria dos plantios comerciais brasileiros. Nas folhas, os sintomas de antracnose compreendem lesões pardas que predominam nos bordos foliares ou junto às nervuras, podendo coalescer e afetar grande parte do limbo foliar $(9,12)$. A incidência da doença aumenta quando as condições ambientais de umidade relativa e temperatura são favoráveis ao desenvolvimento do patógeno (9). Nas espatas ocorrem pequenas manchas escuras, que evoluem para uma podridão encharcada (14).

Pouco se conhece sobre o comportamento de cultivares de antúrio quando infectadas com seus principais patógenos. No Brasil, a cultivar Ômega (IAC 14021) é suscetível à antracnose, sobretudo em locais de elevada precipitação pluviométrica (Tombolato, comunicação pessoal). Entretanto, é desconhecido 0 comportamento das demais cultivares, nacionais ou importadas, utilizadas pelos produtores. Com relação à antracnose, embora ocorra em diversas espécies ornamentais tropicais produtoras de flores e/ou de folhagens, ainda são escassos os trabalhos de comportamento de cultivares. A penas um trabalho realizado em bastão do imperador (6), encontra-se disponível. Desconhece-se também a reação da espata quando inoculada com C. gloeosporioides em diferentes estádios de desenvolvimento.

Nesse trabal ho, os objetivos foram verificar o efeito da idade da espata na suscetibilidade à antracnose; observar a influência da quantidade de ferimentos e época de inoculação no desenvolvimento dos sintomas; verificar o comportamento de cultivares de antúrio quando inoculadas com C. gloeosporioides.

\section{MATERIAL E MÉTODOS}

Obtenção e manutenção dos isolados

Isolados de C. gloeosporioides foram obtidos de lesões em espatas de antúrios cultivados em municípios produtores dos estados do Ceará ( C g 1) e Pernambuco ( $\mathrm{Cg} 2$ e C g 3). F ragmentos de tecido provenientes de lesões presentes nas espatas foram desinfestados em álcool 70\% por 30 segundos, seguido de hipoclorito de sódio (1,5\%) por um minuto. A pós, foram lavados duas vezes em água destilada esterilizada $(A D E)$ e colocados em placas de Petri contendo meio de cul tura batatadextrose-ágar (BDA). A pós obtenção de cultura pura, os isolados foram transferidos para tubos de ensaio contendo meio BDA e mantidos a $6{ }^{\circ} \mathrm{C}$. A ntes dos ensaios, os isolados foram repicados para meio BDA onde permaneceram por sete dias. Todos os experimentos foram conduzidos no Laboratório de Patologia Pós-Colheita da UFRPE, temperatura de $25 \pm 2{ }^{\circ} \mathrm{C}$ com alternância luminosa ( $12 \mathrm{~h}$ claro/12 h escuro).
I dade da espata sobre o desenvolvimento da antracnose

Nesse experimento avaliaram-se três fases de desenvolvimento de hastes florais de antúrio, utilizando-se a cultivar Tropical (espata vermel ha e espádice branca) da empresa holandesaA ntura ${ }^{\circledR}$. A s hastes florais nos estádios 1 (espata fechada), 4 (menos de 2/3 da espádice madura) e 5 (mais de 2/3 da espádice madura), definidos por Souza et al. (11), foram cortadas e enviadas ao laboratório. Estas hastes foram delicadamente lavadas com água e sabão e, posteriormente, dispostas a secar a temperatura de laboratório $\left(25 \pm 2^{\circ} \mathrm{C}\right)$. D urante o experimento as bases das hastes ficaram imersas em bal des plásticos com água. Em seguida, as espatas foram feridas com estilete e inoculadas com um disco de meio de cultura BDA de 0,5 cm de diâmetro contendo estruturas do patógeno. A pós inoculadas foram acondicionadas em sacos plásticos contendo al godão umedecido em A DE, constituindo uma câmara úmida por 48 horas. Os isolados utilizados foram o $\mathrm{Cg} 2$ e o $\mathrm{Cg} 3$ provenientes de antúrios cultivados nos municípios de A Ideia - PE e Paulista - PE, respectivamente.

E feito da quantidade de pontos de inoculação de Colletotrichum gloeosporioides

A influência da quantidade de pontos de inoculação na severidade da antracnose em espata de antúrio foi também avaliada nesse experimento, utilizando-se as cultivares Tropical e Cananéia (espata branca e espádice rosa - IAC 16772) proveniente do Instituto A gronômico de Campinas (IA C). A s hastes florais foram cortadas no ponto de colheita e enviadas ao laboratório conforme experimento anterior. Em seguida, as espatas receberam um, três e cinco furos realizados com auxílio de um estilete, sendo posteriormente inoculadas com um disco de meio BDA $0,5 \mathrm{~cm}$ de diâmetro contendo as estruturas deC. gloeosporioides. A s hastes inoculadas foram acondicionadas em sacos plásticos com algodão umedecido em ADE, constituindo uma câmara úmida durante 48 horas. Os isolados utilizados foram o $\mathrm{Cg} 1 \mathrm{e}$ $\mathrm{Cg}$ 2, provenientes dos municípios de Guaramiranga-CE eA Ideia-PE, respectivamente.

E feito da época de inoculação de Colletotrichum gloeosporioides em antúrio

A influência do momento de inoculação na severidade da lesão em espata de antúrio foi avaliada, sendo utilizadas as cultivares T ropical e Cananéia. A s hastes florais foram cortadas, lavadas e acondicionadas conforme descrito anteriormente. Em seguida, as espatas foram feridas com estilete e inoculadas com os mesmos isolados do experimento anterior em épocas diferentes: imediatamente ou duas horas após o ferimento, com disco de $0,5 \mathrm{~cm}$ de diâmetro de meio BDA e estruturas do patógeno. As hastes inoculadas foram acondicionadas em sacos plásticos com al godão umedecido em A DE, constituindo uma câmara úmida por 48 horas.

Reação de cultivares de antúrio à infecção de Colletotrichum gloeosporioides

Foram avaliadas inflorescências de oito cultivares de antúrio, sendo utilizadas as hastes florais de T ropical, M idori (espata verde e espádice branco e verde), L aguna (espata verde e espádice rosa e verde), Farao (espata verde e vermel ho e espádice) e Sonate (espata rosa e espádice rosa) da empresa holandesa $A$ ntura ${ }^{\circledR}$ e $N$ etuno (espata vermel ho escuro e espádice branco e amarelo - IAC 154), A stral (IAC 154 espata vermelho claro e espádice branco e amarelo) e Cananéia provenientes do IA C. A s hastes florais foram cortadas no estádio de espata aberta e até $50 \%$ da espádice madura. Em laboratório, as hastes foram lavadas com água e sabão, dispostas a secar a temperatura ambiente e colocadas 
em baldes plásticos com água de torneira, onde permaneceram durante o experimento. Em seguida, as espatas foram feridas e inoculadas conforme descrito no item anterior. A s hastes inoculadas permaneceram em câmara úmida por 48 horas. Os isolados utilizados foram o $\mathrm{Cg} 1 \mathrm{e}$ Cg 2 .

\section{A nálise experimental}

A unidade experimental em todos os experimentos consistiu de uma haste floral, sendo utilizado o delineamento inteiramente casual izado e 12 repetições. A severidade dos sintomas foi quantificada através da média da medida do diâmetro da lesão no comprimento ena largura, avaliada em centímetros. A avaliação foi realizada em um, três e cinco dias após a inoculação no experimento de idade da espata. N os demais experimentos as espatas foram avaliadas em um, três, cinco e sete dias após a inoculação, sendo o último experimento (reação de cultivares) também avaliado aos nove dias após a inoculação. Com as médias dos dados obtidos foi calculada a área abaixo da curva de progresso da doença (A A CPD) em todos os ensaios conduzidos. No experimento com cultivares também foi avaliado o período de incubação $(\mathrm{PI})$, que compreende o período entre a inoculação e o aparecimento dos sintomas. Os dados foram submetidos à análise de variância e as médias separadas pelo teste de $D$ uncan $(P<5 \%)$. Também foi realizada a análise de correlação de Pearson entre os dados de período de incubação, severidade no último dia de avaliação e a A A CPD com os dados do último experimento.

\section{RESULTADOS E DISCUSSÃO}

I dade da espata sobre o desenvolvimento da antracnose

A idade da espata influenciou no desenvolvimento da lesão para os dois isolados de C. gloeosporioides avaliados. Em hastes com as espatas fechadas, as lesões formadas foram significativamente maiores do que aquel as formadas em espatas nos estádios 4 e 5.0 tamanho das lesões em espatas no estádio 4 não diferiu daquele formado em espatas no estádio 5, para os dois isolados utilizados (Figura 1).

Resultados similares foram observados em plantas de pimentão (C apsicum annum L .) em diferentes idades de desenvolvimento quando

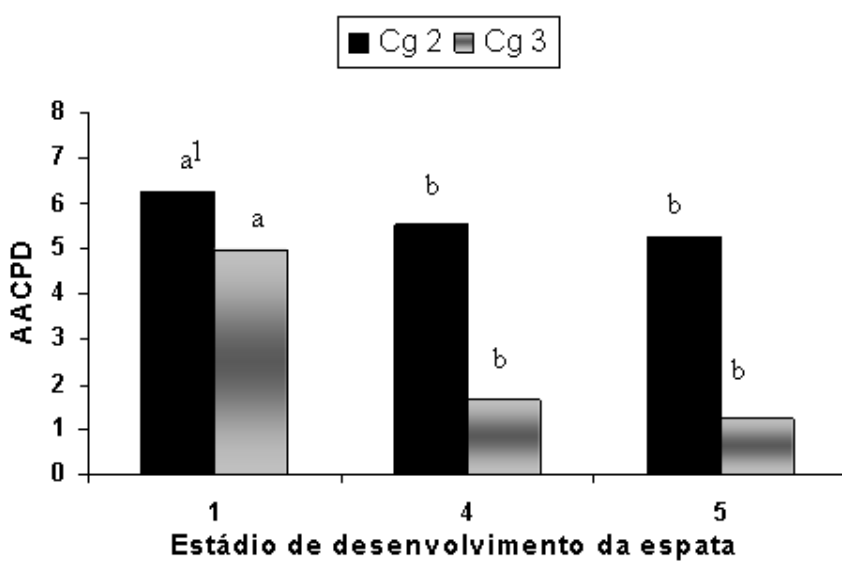

r Igura 1 . Intiuencia aa Iaade de aesenvolvimento aa espata na area apaxo da curva de progresso da doença (AACPD) da antracnose na cultivar Tropical de antúrio, inoculada com dois isolados ( $\mathrm{Cg} 2$ e Cg3) de Colletotrichum gloeosporioides. 1 = espata fechada; 4 = menos de $2 / 3$ da espádice madura; 5 = mais de $2 / 3$ da espádice madura. ${ }^{1} \mathrm{M}$ édias com mesma letra entre os estádios de desenvolvimento não diferem entre si pelo teste de Ducan a $5 \%$ de probabilidade. inoculadas com Colletotrichum coccodes (Wallr.) S. Hughes através de pulverização da parte aérea. Plantas no estádio de duas fol has morreram quando inoculadas com o patógeno, enquanto que no estádio de oito folhas foi verificada apenas a formação de pequenas lesões circulares (5). Esse comportamento de suscetibilidade em antúrio condiz com um dos três padrões citados por A grios (1) de que al gumas plantas são suscetíveis no período inicial de desenvolvimento, tornando-se resistentes no final.

E feito da quantidade de pontos de inoculação de Colletotrichum gloeosporioides

A quantidade de pontos de ferimento para a inoculação influenciou diretamente no desenvolvimento das lesões provocadas por $C$. gloeosporioides em espatas de antúrio (Figura 2). As maiores lesões foram formadas com cinco pontos de ferimento nas duas cultivares e com os dois isolados utilizados. Essas lesões diferiram significativamente daquelas formadas com três e com um ponto de ferimento antes da inoculação.

A elevação da severidade da doença, com o maior número de pontos de inoculação, pode ser explicada pela quantidade de aberturas disponíveis para a penetração, potencializando a ação do patógeno através de infecções simultâneas em uma pequena área. E $m$ frutos de meloeiro inoculados com M yrothecium roridum Tode ex Fries, a severidade observada acompanhou a quanti dade de pontos de ferimento, sendo maior em locais com dez pontos, independente do isolado e da cultivar avaliados (10).

É poca de inoculação de Colletotrichum gloeosporioides em antúrio
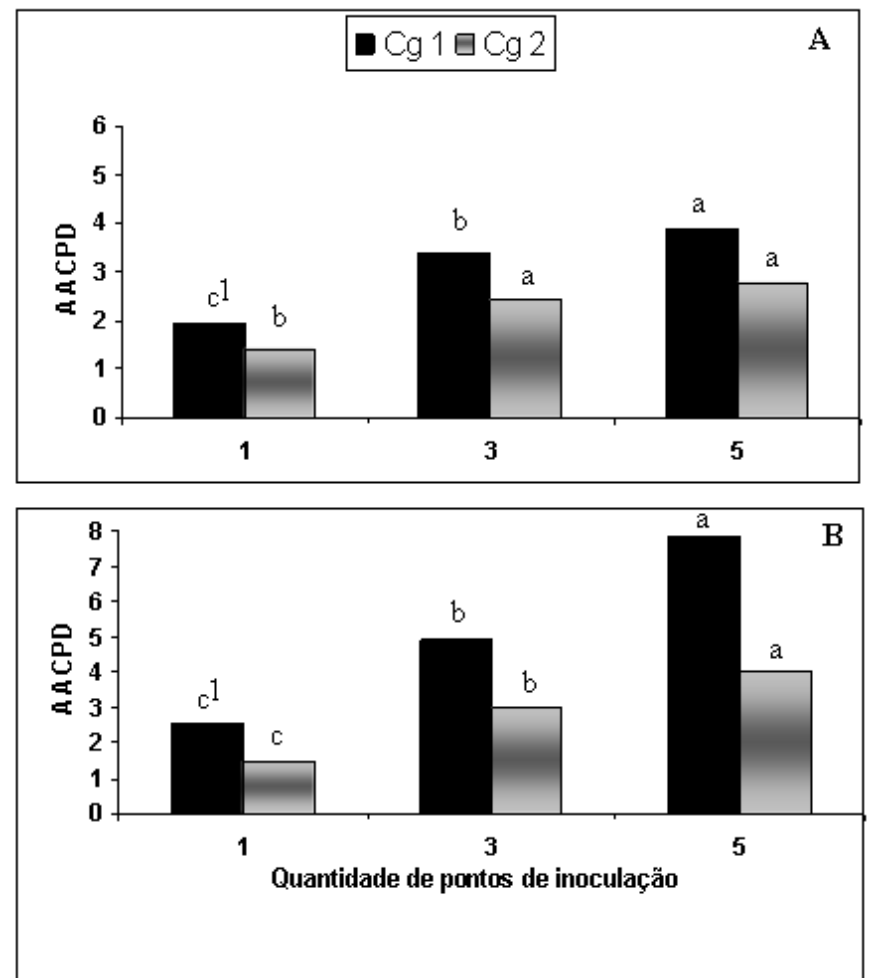

Figura 2. Influência da quantidade de pontos de inoculação na área abaixo da curva de progresso da doença (AACPD) da antracnose em espatas das cultivares Cananéia (A) e Tropical (B) de antúrio, inoculadas com dois isolados ( $\mathrm{Cg} 1$ e $\mathrm{Cg} 3$ ) de Colletotrichum gloeosporioides. ${ }^{1} \mathrm{M}$ édias com a mesma letra entre a quantidade de pontos de inoculação não diferem entre si pelo teste de Ducan a $5 \%$ de probabilidade. 
Tabela 1. Período de incubação - PI (horas), severidade $(\mathrm{cm})$ e área abaixo da curva de progresso da doença (A ACPD) da antracnose em espatas de cultivares de antúrio inoculadas com dois isolados de Colletotrichum gloeosporioides $(\mathrm{Cg})$

\begin{tabular}{|c|c|c|c|c|c|c|}
\hline \multicolumn{4}{|c|}{ I solado Cg 1} & \multicolumn{3}{|c|}{ I solado Cg 2} \\
\hline Cananéia & $38,00^{1} \mathrm{a}$ & $0,55 a b$ & 3,46 bc & $66,00 \mathrm{a}$ & $0,83 a b$ & $4,45 a b$ \\
\hline A stral & $14,00 \mathrm{~b}$ & $0,58 a b$ & $4,42 a b$ & 17,00 de & $0,69 a b c$ & 5,14 a \\
\hline Tropical & $12,00 \mathrm{~b}$ & $0,73 a$ & $5,08 \mathrm{a}$ & $13,00 \mathrm{e}$ & $0,73 a b$ & $5,05 \mathrm{a}$ \\
\hline Laguna & $37,00 \mathrm{a}$ & $0,56 a b$ & $3,18 \mathrm{c}$ & $51,00 \mathrm{~b}$ & $0,66 \mathrm{bc}$ & $3,23 \mathrm{~cd}$ \\
\hline M idori & $36,00 \mathrm{a}$ & $0,59 a b$ & $3,71 b c$ & $59,00 \mathrm{a}$ & $0,50 \mathrm{c}$ & $2,65 d$ \\
\hline CV $(\%)$ & 34,09 & 33,45 & 33,31 & 28,74 & 32,31 & 25,88 \\
\hline
\end{tabular}

${ }^{1} M$ édias com a mesma letra não diferem entre si pelo teste de Duncan a $5 \%$ de probabilidade.

A época de inoculação não diferiu nas duas cultivares avaliadas, ou seja, a severidade observada com a inoculação após o ferimento ou somente duas horas depois foi a mesma. Também não houve diferença quando se compararam as cultivares $C$ ananéia e Tropical no momento zero de inoculação e após duas horas do ferimento. Provavelmente, esse fato se deve ao aumento da síntese de etileno por ocasião dos ferimentos, o que propicia a senescência do tecido que pode permanecer suscetível por um maior espaço de tempo.

Resposta de cultivares de antúrio a infecção de Colletotrichum gloeosporioides

As cultivares de antúrio avaliadas comportaram-se de modo diferente quanto ao período de incubação (PI), a severidade (SEV) e a área abaixo da curva de progresso da doença (A A CPD) (Tabela 1). Os menores PI para o isolado $\mathrm{Cg} 1$ foram observados nas cultivares $\mathrm{A}$ stral, Tropical, Netuno e Farao, diferindo significativamente nas demais cultivares. Esse período variou de 12 a 44 horas nas cultivares Tropical e Sonate, respectivamente. $\mathrm{N}$ as cultivares Sonate, A stral, Tropical, Netuno e Farao foram observados os menores PI para o isolado $\mathrm{Cg} 2$. Esses períodos variaram de 13 horas, nas cultivares Tropical e F arao, a 66 horas na cultivar Cananéia.

Os isolados se comportaram de maneira diferente quando inoculados em cultivares de antúrio (Tabela 1). 0 menor valor de severidade ocasionado pelo isolado $\mathrm{Cg} 1$ foi observado na cultivar Sonate, que diferiu significativamente das demais cultivares. Para o isolado $\mathrm{Cg}$ 2, os menores valores de severidade foram observados em Farao e Midori.

A severidade das lesões também foi avaliada pelo cálculo da área abaixo da curva de progresso da doença (A A CPD) (Tabela 1). A menor A A CPD resultante da inoculação com Cgl foi observada em Sonate,

Tabela 2. Coeficiente de correlação entre o período de incubação (PI), a severidade da lesão (SEV) e a área abaixo da curva de progresso da doença (AACPD) dos isolados $\mathrm{Cg} 1$ e $\mathrm{Cg} 2$ de Colletotrichum gloeosporioides em cultivares de antúrio

\begin{tabular}{|c|c|c|c|c|c|}
\hline \multicolumn{3}{|c|}{$\mathrm{Cg} 1$} & \multicolumn{3}{|c|}{$\mathrm{Cg} 2$} \\
\hline & SEV $(\mathrm{cm})$ & AACPD & & $\mathrm{SEV}(\mathrm{cm})$ & AACPD \\
\hline PI (horas) & $-0,46 *$ & $-0,63^{*}$ & PI (horas) & $-0,08^{\mathrm{NS}}$ & $-0,44^{*}$ \\
\hline $\mathrm{SEV}(\mathrm{cm})$ & - & $0,88^{*}$ & SEV $(\mathrm{cm})$ & - & $0,85^{*}$ \\
\hline$A A C P D$ & - & - & AACPD & - & - \\
\hline
\end{tabular}

* Significativo a $5 \%$ de probabilidade pelo teste t; ${ }^{\text {NS }} \mathrm{N}$ ão significativo. que diferiu das demais cultivares. A s menores A ACPD ocasionadas pelo isolado $\mathrm{Cg} 2$ foram observadas em L aguna e M idori, que diferiram das cultivares Cananéia, A stral, Sonate, Tropical e N etuno.

Os valores obtidos por análise de correlação entre o período de incubação e a severidade das lesões, bem como entre o período de incubação e a A A CPD foram negativos para o isolado Cg 1, indicando que quanto menor o período de incubação, maiores serão os valores de severidade eAA CPD (Tabela 2). R esultado similar foi observado para 0 isolado C 2 onde a correlação entre o período de incubação e a A ACPD também foi negativa. As análises entre a severidade e a A A CPD foram positivas para os dois isolados avaliados.

A s principais cultivares de bastão do imperador (Etlingera elatior (J ack) Smith) comportaram-se de maneira diferente quando inoculadas com C. gloeosporioides. Foi observado que as lesões formadas na cultivar vermelha (Red Torch) apresentavam o dobro do tamanho daquelas formadas na cultivar porcelana (Porcelain), sendo que nesta o patógeno não se desenvolveu quando inoculado sem ferimento (6). Cultivares da planta ornamental cartamus (Carthamus tinctorius L.) também responderam de forma diferente quando naturalmente infectadas com Colletotrichum acutatum Simmonds no campo. A incidência da doença variou de 27,6 a 97,1\% e a severidade de 2,0 a 3,5 nas sete cultivares avaliadas (8).

Dessa forma, a idade da espata, a quantidade de pontos de ferimento para a inoculação, a cultivar e o isolado utilizado podem influenciar no desenvol vimento da antracnose em espatas de antúrio, porém o mesmo não ocorre para a época de inoculação.

\section{REFERÊNCIASBIBLIOGRÁFICAS}

1. Agrios, G. N. Plant pathology. San Diego: A cademic Press, 2005. $922 \mathrm{p}$.

2. A morim, E.P. R. Ocorrência de Pestalotiopsis guepinii (Sin. Pestalotia guepinii) em antúrio (Anthurium andraeanum) no B rasil. Summa Phytopathologica, Jaboticabal, v.25, p.363-364, 1999.

3. Freitas-A stúa, J.; Caldari J r., P.; Giória, R. Doenças das plantas ornamentais. In: K imati, H.; A morim, L.; Bergamin Filho, A.; Camargo, L. E. A.; Rezende, J. A. M. M anual de fitopatologia: doenças das plantas cultivadas. São Paulo: Agronômica Ceres, 2005. p.523-539.

4. Fukui, H.; Alvarez, A. M.; Fukui, R. Differential susceptibility of anthurium cultivars to bacterial blight in foliar and systemic infection phases. Plant Disease, Saint Paul, v.82, p.800-806, 1998. 
5. Hong, J. K.; Hwang, B. K. Influence of inoculum density, wetness, duration, plant age, inoculation method, and cultivar resistance on infection of pepper plants by Colletotrichum coccodes. Plant Disease, Saint Paul, v.82, p.1079-1083, 1998.

6. Lins, S. R. 0.; Coelho, R. S. B. A ntracnose em inflorescências de bastão do imperador (Etlingera elatior): ocorrência e métodos de inoculação. Summa Phytopathologica, B otucatu, v.29, p.355358, 2003.

7. Lorenzi, H.; Souza, H. M. Plantas ornamentais no Brasil: arbustivas, herbáceas e trepadeiras. Nova O dessa: Instituto Plantarum, 2001. 1120 p.

8. Park, S. D.; Park, K. S.; Kim, K. J.; K im, J. C.; Yoon, J. T.; K han, $Z$. Effect of sowing time on development of safflower anthracnose disease and degree of resistance in various cultivars. J ournal of Phytopathology, Berlin, v.153, p.48-51, 2005.

9. Pitta, G. P. B.; Cardoso, E. J. B. N.; Cardoso, R. M. G. Doenças das plantas ornamentais. São Paulo: Instituto Brasileiro do Livro Científico, 1990. 174p.

10. Senhor, R. F.; E pidemiologia da podridão-de-cratera em frutos de meloeiro. 2006. 76 f. Dissertação (M estrado em Fitossa- nidade) - Universidade Federal Rural de Pernambuco, Recife.

11. Souza, J. W. O.; Pinheiro, P. G. L.; Loges, V.; Castro, A. C. R.; Lira Júnior, M. A. Desenvolvimento de inflorescências de Heliconia, Anthurium andraeanum e Renanthera coccinea em Pernambuco. In: Congresso brasileiro de floricultura e plantas ornamentais, 14., 2003, Lavras, M G. Anais... Lavras: Sociedade Brasileira de Floricultura e Plantas Ornamentais, 2003. p. 394.

12. Tombolato, A. F.; Furlani, P. R., Castro, C. E. F.; M athes, L. A. F.; Tagliacozzo, G. M. D.; Saes, L.A.; Rivas, E. B.; Coutinho, L. N.; Bergman, E. C.; Imenes, S. L.; Costa, A. M. M..; Leme, J. M. Antúrio (Anthurium andraeanum Lindl.). In: Tombolato, A. F. Cultivo comercial de plantas ornamentais. Campinas: Instituto A gronômico, 2004. p. 61-94.

13. Van Herk, M.; Van Koppen, M.; Smeding, S.; Van Der Elzen, C. J.; Van Rosmalen, N.; Van Dijk, J.; Lont, A.; Van Spingelen, J. Cultivation guide anthurium: global know-how for growers around the globe. Bleiswijk: A nthura B. V., 1998. 140 p.

14. Warumby, J. F.; Coelho, R. S. B.; Lins, S. R. O. Principais doenças e pragas em flores tropicais no Estado de Pernambuco. Recife: Sebrae, 2004. 98 p. 